\title{
When outreach in optics meets architecture: the optical terrace
}

Guillaume Allain, Jean-Christophe Gauthier, Madison Rilling, Frédéric Jobin, Olivier Boily, et al.

Guillaume Allain, Jean-Christophe Gauthier, Madison Rilling, Frédéric Jobin, Olivier Boily, Antoine Michel, Isabelle Jobin, "When outreach in optics meets architecture: the optical terrace," Proc. SPIE 11143, Fifteenth Conference on Education and Training in Optics and Photonics: ETOP 2019, 111431S (2 July 2019); doi: 10.1117/12.2523807

Event: Fifteenth Conference on Education and Training in Optics and Photonics: ETOP 2019, 2019, Quebec City, Quebec, Canada 


\title{
When outreach in optics meets architecture: The Optical Terrace
}

\author{
Guillaume Allain ${ }^{1,2}$, Jean-Christophe Gauthier ${ }^{1,2}$, Madison Rilling ${ }^{1,2}$, Frédéric Jobin ${ }^{1,2}$, Olivier \\ Boily $^{1,2}$, Antoine Michel ${ }^{1,3}$, and Isabelle Jobin ${ }^{1,3}$ \\ ${ }^{1}$ Centre d'optique, photonique et laser, Québec City, QC, Canada \\ ${ }^{2}$ Départment de physique, de génie physique et d'optique, Université Laval, Québec City, QC, \\ Canada \\ ${ }^{3}$ École d'architecture de l'Université Laval, Université Laval, Québec City, QC, Canada
}

\begin{abstract}
At the end of 2017, Université Laval's SPIE Student Chapter set out to imagine a large-scale outreach initiative that would be artistic in its form, while being educational in its mission. With UNESCO's first International Day of Light (IDL) acting as a catalyst, The Optical Terrace (La Terrasse Optique, in French) came to life. The first edition of The Optical Terrace was a standalone platform made of three separate 8-ft wooden cubic structures where people could learn about light phenomena through interactive experiments. This project originated from dedicated volunteer work of a multidisciplinary group of students in physics and architecture. Project funding was made possible through financial support from professional societies (SPIE and OSA) and through partnerships with local optics and photonics companies.

In this paper, we present The Optical Terrace as an original example of a large-scale outreach project, educational for both children and adults. It is a student initiative with a long-term high impact potential which, however, does not require continual in-person involvement. By installing the structure in popular and touristic locations within the city, this out-of-the-box initiative is a creative means for teaching the general public about the importance of optics and photonics. Based on the success and lessons learned from the first edition, a new and improved design was designed and built in time for IDL 2019.
\end{abstract}

Keywords: Science Outreach, Science Exhibit, Art and Science, Education and Training in Optics and Photonics, Student Chapter, Student Initiative, International Day of Light

\section{INTRODUCTION}

Even if Optics and Photonics (O\&P) is a fascinating area of physics with a huge economical impact in a few cities in North America, it remains largely unknown to the general public.This is especially true in Québec City, as our student chapter realized through its various outreach activities over the last 10 years. One of the main objective of our student chapter is investing energy into outreach activities to show the importance of O\&P in our daily lives. Invested in promoting the importance of O\&P in society and everyday life, Université Laval's joint The Optical Society (OSA) and SPIE student chapter, the Regroupement des étudiants en photonique et optique de Laval (REPOL) wanted to create a way to reach people outside of the traditional channels like schools, museums or libraries. In these standard settings, we noticed that it was difficult to reach people that were not already interested in science. Therefore, we proposed to combine science outreach with architecture in public open spaces to stimulate curiosity and interest regardless of the people's background.

This proceeding will show the steps the student chapter has taken in order to realize this very large project. We will expose the details of our organization, the different steps and obstacles we had to tackle leading to the building of the structure and finally our conclusions on these types of project. Through this, we hope to inspire other students chapter to design these kind of projects because they allow relatively small committees to have a large impact on their community.

Further author information: (Send correspondence to Guillaume Allain)

Guillaume Allain: e-mail: guillaume.allain.1@ulaval.ca

Fifteenth Conference on Education and Training in Optics and Photonics: ETOP 2019, edited by

Anne-Sophie Poulin-Girard, Joseph A. Shaw, Proc. of SPIE Vol. 11143, 111431S · C 2019

SPIE, ICO, IEEE, OSA · CCC code: 0277-786X/19/\$18 · doi: 10.1117/12.2523807

Proc. of SPIE Vol. 11143 111431S-1

Downloaded From: https://www.spiedigitallibrary.org/conference-proceedings-of-spie on 26 Apr 2023 


\section{DEVELOPMENT}

\subsection{Organizational structure}

One of the main challenges with such a large-scale project is the management, both technical and logistical, of all the different elements which make up its realization. The main aim of The Optical Terrace was to increase the awareness of the population of Québec City about the importance of light in various aspects of everyday life through an open, architectural structure that would house large-scale, interactive experiments. Our joint SPIE and OSA student chapter, which piloted the project, already had some valuable experience in organizing public outreach activities ${ }^{1,2}$ which shared some similarities with the concept of The Optical Terrace. Based on our previous experience, forming a dedicated committee for the project within the REPOL, which would recruit students from outside the chapter's executive committee, was the best way to operate. In previous outreach projects, all organizing members were members of the REPOL, meaning that they all studied in optics and photonics and shared similar backgrounds. However, this project required students with a training in architecture to design the structure itself. We thus recruited two students from Université Laval's school of architecture who would be responsible for this essential aspect of the project.

To maximize efficiency, we created small teams that would each work on a specific section of the structure:

1. Project management (3 members)

2. Architectural design (2 members)

3. Experiment design (4 members)

4. Logistics (2 members)

In addition to these dedicated teams, the REPOL's treasurer monitored the project's expenses and its funding. The role of the management team was to lead and support the project by doing most of the administrative work, such as finding and booking public spaces to occupy, getting the structure insured in case of vandalism or civil liability, and finding funding from academic and private sources. Above all, their main task was overseeing the work and progress of the different teams and making sure that the project's timeline, budget, design requirements and mission were all respected over the course of its development. This was achieved by holding regular meetings and by directly assisting the teams in various ways as needed.

The experiment design team oversaw the most crucial part of The Optical Terrace, i.e., the outreach experiments. They made sure that the human-scaled interactive stations with different optical phenomena were fun, understandable and easy to use for visitors of all ages. They were also responsible for finding all materials and overseeing the integration with the architectural design team to ensure that as few complications as possible would arise during the construction.

The addition of an architectural team, made up of two students from Université Laval's school of architecture, was the main difference with our chapter's previous outreach projects. The multidisciplinarity of the project, mainly between physics, education and architecture, meant that we were pushed outside of our comfort zone and needed to find and use resources and expertise beyond those of our student chapter. Moreover, having people with vastly different backgrounds helped enormously during the design phase, namely by bringing constant feedback on concepts that were not familiar to most physicists on the team such as user experience, user interaction and visual identity.

The logistics team was formed during the last phase of the project once the design of the structure was completed. This team was to help in building the structure itself, integrating the experiments within the platform and organizing the terrace's opening ceremony, which was to take place on May 16, 2018. 


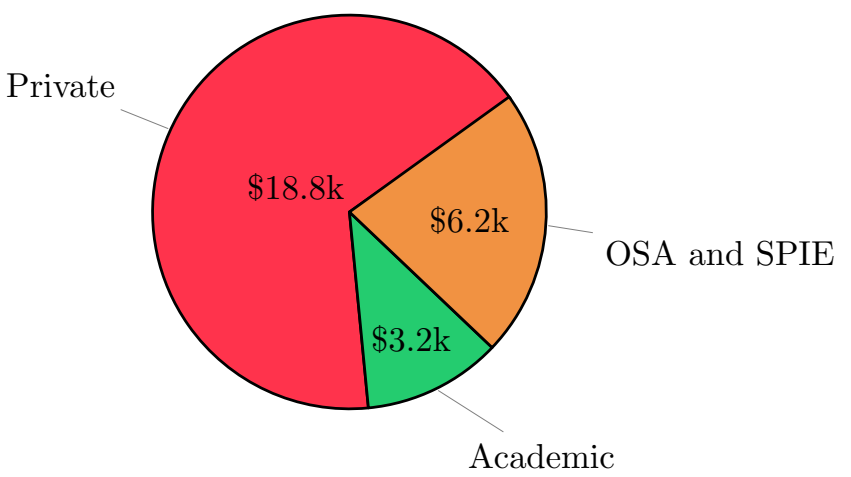

Figure 1: Sources of funding (in $C A D$ ) for a total of $\$ 28138$

\subsection{Project funding}

The call for SPIE's International Day of Light (IDL) Micro Grants (\$3 000 USD) was the actual initiator of the brainstorming session which led to The Optical Terrace. Receiving the micro grant for an IDL initiative then incited OSA to contribute a similar amount. These funds were instrumental in the realization of the initial ideas that we had for the experiments. It is important to note that very early funding is critical for the success of these types of projects because ordering samples of material or building small-scale test versions of the structure can get quite expensive, especially if the chapter or organizing committee doesn't have the necessary cash flow. A small line of credit or a loan can also be an option to help with these problems if additional funding is confirmed, but still being processed.

We soon realized that our ambitions for the project greatly surpassed that of the initial round of funding we had received. In order to obtain more funding, the first step was to elaborate a partnership plan that would propose exposure to local industries and academic partners in exchange for funding. This kind of partnership was in line with a secondary goal of the project, which was to promote Québec City's O\&P sector. Being the first large-scale project with the ambition of democratizing $\mathrm{O} \& \mathrm{P}$ to the general public in years, it was not difficult to get a sizable amount of funding from the private sector. Three different partnership levels were offered to our partners, where the highest level associated the partner's name with one of the interactive stations.

\subsection{Design}

The design phase was one of the most challenging aspects, as students could only be invested part-time in the project and different complexities arose from combining disciplines. To create a coherent framework for the project development, we defined clear requirements that would hold each team accountable and allow the whole project to come together smoothly during its final integration phase. An open and flexible approach with only high-level requirements was chosen to guide the success of the project, which allowed to try novel ideas at almost any point in the process. Here is a summary of these guiding principles:

1. The Optical Terrace will be a way for the public to learn about the role of O\&P in their everyday lives;

2. The Optical Terrace will be an urban public space for the general public to enjoy visiting;

3. The Optical Terrace will house human-scaled experiments with which the public can interact directly;

4. The experiments will be kept simple enough so that a child can grasp a coarse understanding of the physical phenomena at play.

Since the development of the project was done on a tight schedule, i.e., over the course of only three months, the experiments and the structure were designed in parallel, nearly at the same time. This allowed to adjust the structure design as the experiments took form. On the other hand, this way of creating the design also brought a lot of back and forth discussions due to design changes from one side or the other, sometimes leading to confusion between the teams. 


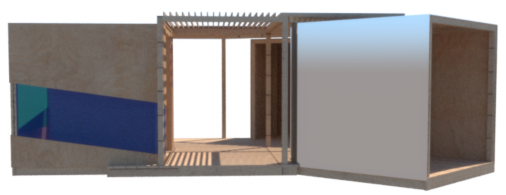

(a) Side view

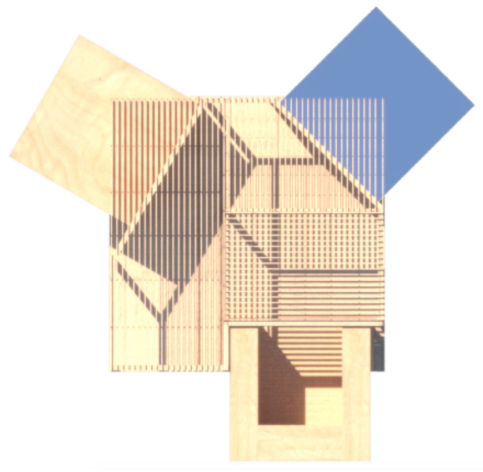

(b) Top view

Figure 2: Render of The Optical Terrace.

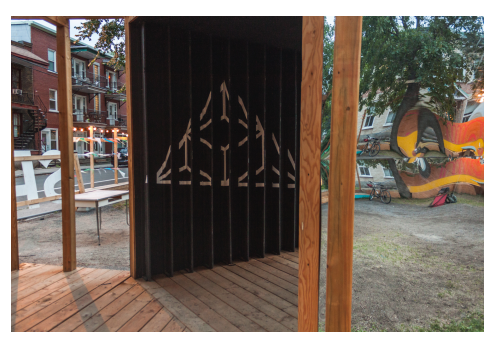

(a) Left wall, when standing at a nonideal observation point.
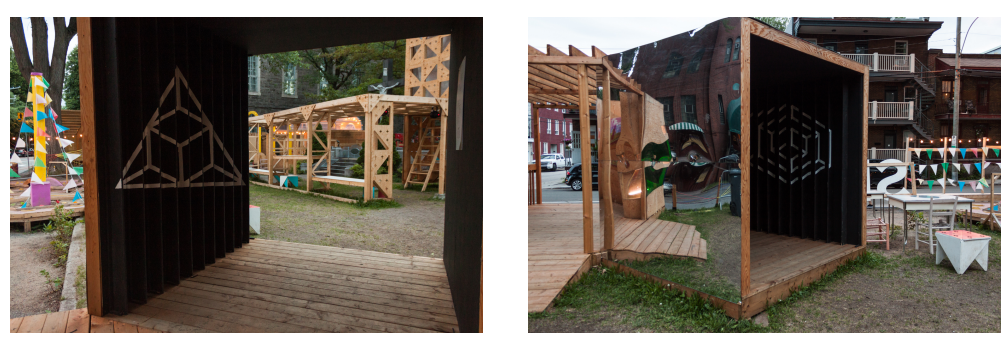

(b) Left wall, when standing at an ideal observation point. (c) Right wall, when standing at a nonideal observation point

Figure 3: The perspective experiment.

\subsubsection{Structure}

We had two main goals with the structure: (1) to house the experiments in an interesting and unique way, and (2) to spark curiosity in people who would see it from a certain distance. We required that the structure be movable, since it would be installed in two different public locations over the course of the summer. Also, we required that the experiments within the structure be easily alterable in case something happened during construction and that an experiment could not be used. The work was mainly done by the students in architecture with input from the rest of the organizing committee to guide the integration of the experiments within the structure.

The final design of The Optical Terrace is shown in figure 2. The overall design of the structure was meant to be simple yet intriguing. Mainly, the goal was to create experiments at a human scale so that a visitor of the terrace be a user and not only an observer. With the experiments described in the following section, people were encouraged to move things directly or to move around to find an ideal viewpoint, allowing them to learn about optical phenomena in fun and active ways. Three large boxes, also referred to as stations, were oriented in such a way that they encouraged wandering between the different experiments of the structure. A large platform connected these three spaces, and a large pergola acted as a common roof, giving the impression that the three experiments were parts of a coherent and unified space, together forming The Optical terrace.

\subsubsection{Experiments}

Since the goal was to teach the general public about simple optical phenomena that they can encounter in their everyday life, we aimed for our experiments to be understood to a certain level by a child in the last year of grade school. Also, we wanted people to interact directly and easily with the experiments. With these requirements and the general shape of the structure devised, we designed three experiments, subsequently referred to as perspective, polarization and spectroscopy.

The perspective experiment can be seen in Figure 6, as integrated in the final structure. The effect relies on the anamorphic projection of geometrical shapes on a wall. Using baffles, we were able to project two different 


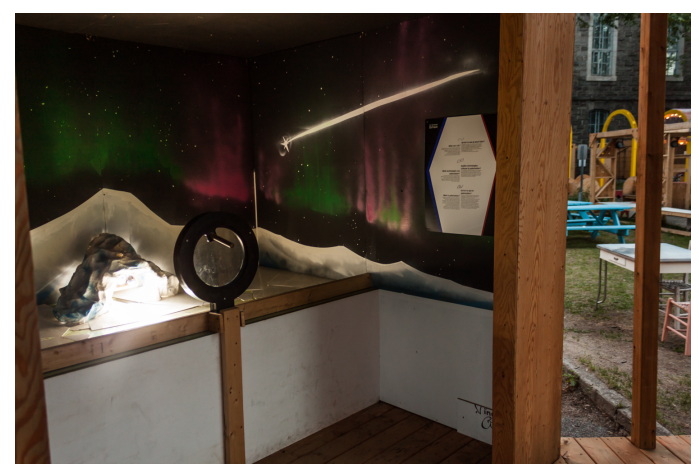

Figure 4: The polarization experiment. Users could turn the wheel to filter the light reflected off the plastic surface.
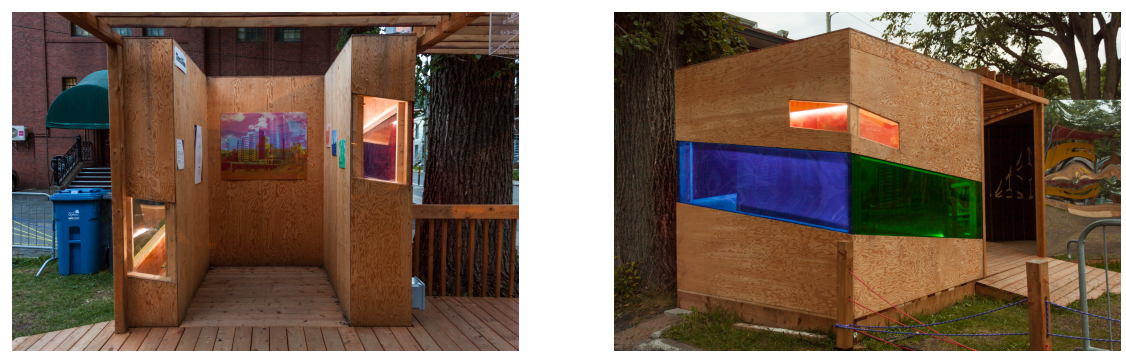

(a) The inside of the station allowed visi- (b) By walking around the station, vistors to view the original composite image. itors would see different images depending on which colored window they looked through.

Figure 5: The spectroscopy experiment.

shapes on the same wall depending on the orientation of the observer. We instructed the viewer to move around The Optical Terrace to find the exact position where the deformation is minimal, allowing them to see the original image.

The polarization experiment was a challenge to design because we wanted to illustrate this quite complex phenomenon in a simple way. We were inspired by the use of polarizing filters in photography and sunglasses for the suppression of glare on reflective surfaces, such as water. We were inspired by Sentinel North, a research initiative led by Université Laval for technology development for the Canadian North; the theme of the experiment was that of a northern scene showing glaciers and the northern lights. The experiment uses bright lights reflected on a slightly tinted acrylic window under which an image was placed. A custom-made wheel with a polarizing filter could be rotated to suppress the glare from the bright lights.

The third experiment was based on spectroscopy, the science of extracting information from the chromatic components of light. In order to show this in a simple way at a human scale, we decided to use filters (in our case, commercial colored acrylic panels) to view a different image depending on the filter that is placed in front of a composite image. This composite image was made by superposing three grayscale images which were colored according to the different filters that we chose so that only one of these images could be seen through the filter. People were instructed to compare the three images seen through the filters on the faces of the cube to the complete one inside the cube. Clear windows were designed into the structure near the colored windows so that visitors could see both the composite image and the filtered image at the same time.

\subsection{Building and moving The Optical Terrace}

Since we wanted adults to be able to move freely inside the large cubes and not be limited by the height of the ceiling, the scale of the structure was larger than we anticipated. Each cube had a side length of 8 feet, and the whole platform separating them was roughly 16 feet wide. This scale meant that we needed the structure to be 


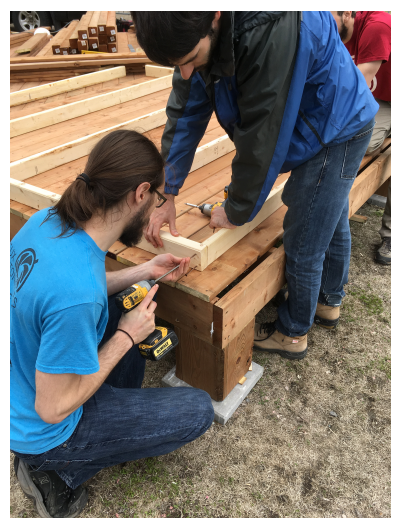

(a) Students during construction

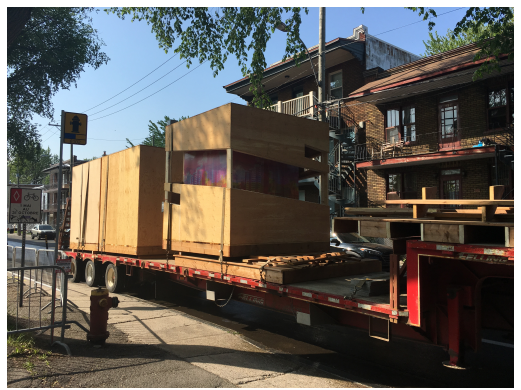

(b) Moving of the structure

Figure 6: Building and moving the structure.

\begin{tabular}{|c|c|}
\hline Nature & number of partners \\
\hline Academic & 4 \\
Industrial & 9 \\
\hline
\end{tabular}

(a) Sources of funding

\begin{tabular}{|c|c|}
\hline Level & Number of partners \\
\hline Platinum $(\$ 7500 \mathrm{CAD})$ & 2 \\
Gold $(\$ 1500 \mathrm{CAD})$ & 4 \\
Silver $(\$ 750 \mathrm{CAD})$ & 7 \\
\hline
\end{tabular}

(b) Partner tiers

Table 1: Sources of funding and partnership levels.

more rigid in order to be safe for every user of the terrace. Since most of our members did not have experience in building this atypical kind of structure, we hired a local contractor for additional help with our plans and to help with the construction. However, we had to make sure that, even if we modified the plans of the terrace, it would still be possible to separate the cubes and the platform in order to move the whole structure to another public space.

Even with this additional help, a large part of the construction was realized by a student workforce, most of them members of the REPOL. The different experiments were integrated inside the Optical Terrace as the cubes were completed. Since we had tested each experiment on a smaller scale in our outreach optics labs, the integration went smoothly, and every experiment scaled as expected.

However, moving this massive structure proved to be a challenge. The weight of the whole terrace, including the cubes, was nearly five tons, which made it impossible to move using standard pick-up trucks or moving trucks without disassembling parts of the cubes or the platform. We thus hired a specialized company to help move the structure from our first public place to the second one. The use of a long platform truck was necessary considering the scale of the structure, along with a large fork-lift to move the cubes onto the truck. These tools, which are typically not available to people outside the construction industry, allowed us to move the structure in the simplest and most secure way we could find.

Even though we planned for the structure to be movable, we had not explicitly specified how it should be moved in our high-level requirements. For projects of this scale, this is definitely an element that should be considered from the get-go as a principal design requirement in order to minimize cost and logistics associated with hiring a specialized moving company.

\section{IMPACT}

\subsection{Partners and visibility}

One of the most important requirements of this project was to promote the importance of the O\&P sector in Québec City's economy. Getting funding for the project in exchange for visibility from these private partners was a perfect solution to involve them in the project. We also opened these partnerships to the academic sector, to give visibility to research centers or initiatives stemming from the Québec city area. 

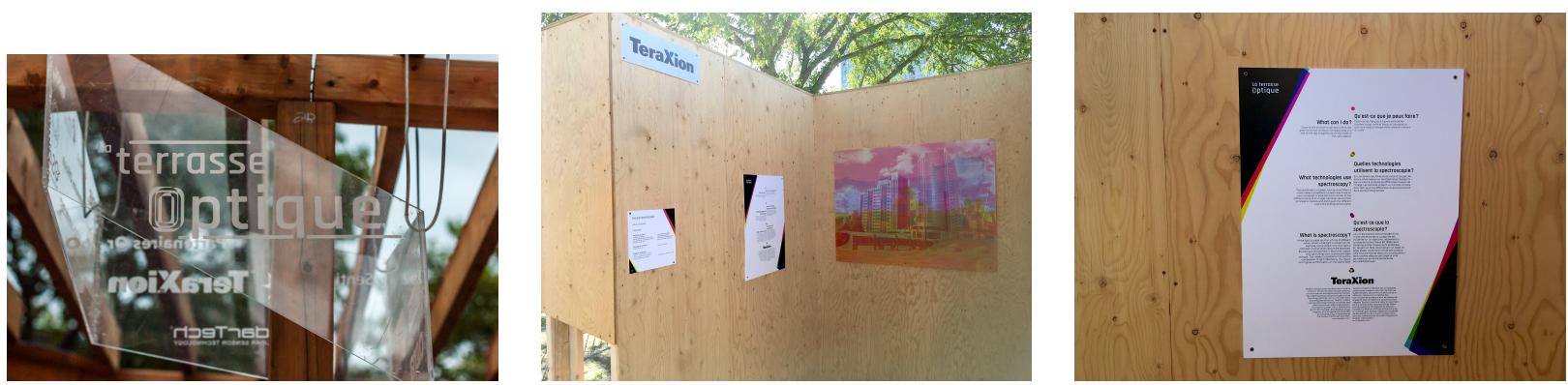

(a) Center post acrylic panels showing (b) An example of a platinum-level (c) An example of partner visibility all of our partner logos. partner's visibility associated with an on an informative panel of the specexperiment. troscopy experiment.

Figure 7: Partner visibility.

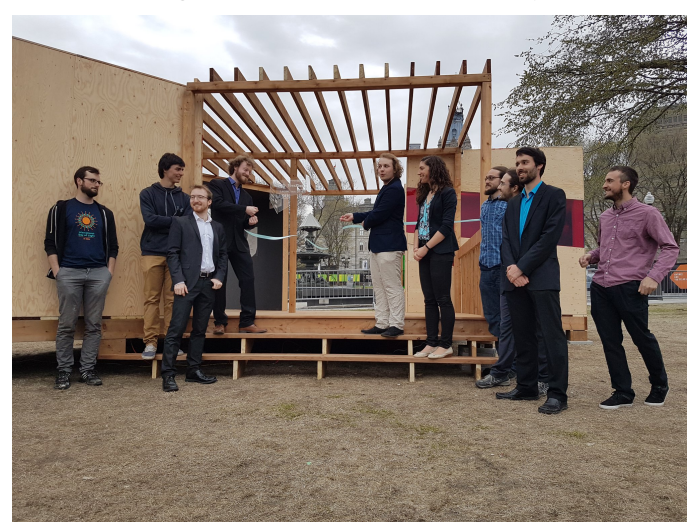

Figure 8: The opening of The Optical Terrace on May 16, 2018, the first IDL.

For this project we split the partnership opportunities in three different levels in order to offer visibility to a larger range of industrial partners. We wanted the public to become familiar with smaller companies as well as larger, and more well known, corporations. We based ourselves on the amount that other, already successful, student-led science outreach projects were offering in exchange for similar visibility. In total, we signed on a total of 13 partners, most of them being silver-level partners. The highest funding level was not something that was originally in our partnership plan; however, as two companies wanted to be more involved in the project and hence have a larger contribution and greater visibility, we changed our plans to include a $\$ 7500 \mathrm{CAD}$ funding level.

The silver and gold levels were differentiated by the size of their logo laser-printed on an acrylic panel (figure 7a). This acrylic panel was at the very center of the three cubes, and visible as soon as you set foot on the terrace. Unfortunately, in retrospect, we found that this was not sufficient to give enough visibility to our partners as people were not as drawn to it as we had expected. A taller structure or a colored one, as opposed to the clear acrylic, would have helped drawing people's attention to the center of the structure, and would have given better visibility to our partners.

The highest platinum level, however, gave the opportunity to sponsor one of the three experiments. This meant that the visual image of the company was attached to the experiment itself (as we can see on Figure $7 \mathrm{~b}$ ) and the explanatory poster included a small paragraph describing the company and their expertise. This kind of visibility was optimal for people interacting directly with the experiments, but much less visible to people simply walking by. For that reason, they were also visible on the center post's acrylic panels.

\subsection{Public events}

Since the main objective of the project was to share the importance of light in our everyday life and to give visibility to the $\mathrm{O} \& \mathrm{P}$ sector in Québec city, we wanted The Optical Terrace to be seen by as many people 

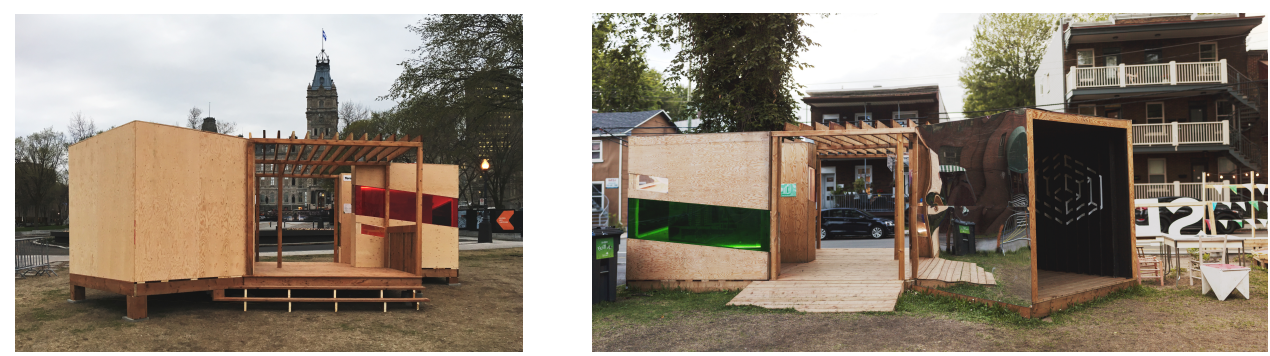

(a) The Optical Terrace installed in (b) The Optical Terrace installed at the SPOT, serving front of Québec's Parliament building. as a main entrance.

Figure 9: The Optical Terrace in its different environments.

as possible. After considering multiple sites, we settled on two of them: a public park in front of Québec's Parliament building, near the touristic Old City, and the Sympathique Place Ouverte à Tous (SPOT), a familyfriendly public place at the heart of one of the city's main neighbourhoods. The grand opening of the terrace took place on the first IDL with the project's partners. At this occasion, we presented the project and discussed student-led outreach initiatives. We received our first official visitors minutes after the grand opening. Having two different public spaces with the terrace present allowed us to tap into two very different markets: tourists visiting the city and citizens of Québec City.

The Optical Terrace was in front of the Parliament building from May 16 till the end of May. It was accessible at the SPOT from mid-June till the end of August. During the times when students were physically present at the terrace, it was observed that tourists seemed much more intrigued by the structure and stopped at the structure to explore the stations. This was less the case when the terrace was at the SPOT. However, it was common to see groups of people simply standing and talking within the structure, using it more as an urban space. The 14 days when the terrace was in front of the parliament building were most likely very effective in terms of visibility for our project and the O\&P sector in general since tours and buses were stopping very close to the structure, allowing a larger number of people to see the terrace.

On the other hand, when we moved the structure to the SPOT, a very different kind public was interacting with the structure. Since most of the users of the SPOT were families looking to relax or were visiting the site for another event, they were less prone to interact with the experiments. This meant that, without active involvement from someone from the team, people were not interacting with the structure as much as expected. However, this observation may in part be due to the fact the many of the same visitors came to the SPOT several times during the summer and had already experienced the structure on their first visit. Nevertheless, The Optical Terrace was well received and well integrated with the SPOT because of its architectural qualities and its color scheme which matched that of the SPOT.

\section{CONCLUSION AND LESSONS LEARNED}

Mostly, the project was a success in its main roles: to share the importance of different light phenomena in our everyday life and of the O\&P sector for the Québec city's economy. Being the first edition of a new kind of project, a few details didn't work out as expected:

- People seemed to be confused by the way the information was presented

- The structure was way more difficult to move than what was originally planned

- Every moving parts of the experiment broke several times

Even though we had a few technical problems, we are confident that a majority of users left the structure with new knowledge regarding light and its importance in their daily lives. A new version of the project will come back during summer 2019, integrating what we learned during the 2018 experience. The team will also expand to include people from user interaction, graphic design and teaching to further broaden our expertise and generate new ideas. 


\section{REFERENCES}

[1] Jean-Christophe Gauthier, Madison Rilling, G. A. F. J. A. C. X. D. S. D. C. F. S. G. S. M. V. M.-B., "An optics and photonics exhibit that reunites, educates and, engages: a meeting with light," (2018).

[2] Anne-Sophie Poulin-Girard, Geneviève Boudreau, J. L. A. V. M.-A. G. G. T. A. A., "Ten years of photonic games: lessons learnt," (2018). 